\title{
Syncope in hypertrophic obstructive cardiomyopathy due to asystole
}

\author{
Simon Joseph, Raphael Balcon, ${ }^{1}$ and Lawson McDonald \\ From the National Heart Hospital and the Institute of Cardiology, London
}

\begin{abstract}
Although faintness, syncope, and sudden death are common in hypertrophic obstructive cardiomyopathy, their cause has not been well documented. The occurrence of ventricular asystole causing syncope after exercise is described in one patient. The elucidation of the disturbance of rhythm may, therefore, be of great importance, as sudden death may be avoided in these patients by the prophylactic use of a pacemaker.
\end{abstract}

Hypertrophic obstructive cardiomyopathy (Goodwin et al., 1960) is now a well-recognized clinical entity. Its clinical and pathological features have been widely described (Brent et al., 1960; Goodwin et al., 1960; Wigle, Heimbecker, and Gunton, 1962; Maurice et al., 1966; Braunwald et al., 1964; Meerschwam, 1969); symptoms include faintness and syncope which are usually related to effort, and though syncope has frequently been reported (Teare, 1958; Brent et al., 1960; Hollman et al., 1960; Meerschwam, 1969), only once has its cause been documented, when ventricular tachycardia and fibrillation were recorded in two patients (Maurice et al., I966). A patient with hypertrophic obstructive cardiomyopathy which was proven by haemodynamic and angiographic studies and subsequently confirmed at operation is described; ventricular asystole occurred after effort and was confirmed by continuous electrocardiographic monitoring.

\section{Case report}

The patient was a 22-year-old Kenyan male of Goanese origin, who had no relevant history apart from bronchial asthma in early life.

He presented at 15 years with cardiac pain and fatigue on exercise. At $\mathbf{I} 7$ he developed episodes of faintness and syncope with effort, and on 12 occasions he had lost consciousness for periods of about one minute. He did not have dyspnoea, palpitation, or epileptic features.

${ }^{1}$ Present address: London Chest Hospital, London Er.
Findings of note on clinical examination were normal arterial pulses, blood pressure 120/75 $\mathrm{mmHg}$, normal jugular venous pressure and pulse, and a hyperkinetic cardiac impulse. The heart sounds were normal and there was a soft midsystolic ejection murmur at the left sternal edge. The heart was slightly enlarged on chest $x$-rays and the appearance of the left border was suggestive of septal hypertrophy; the main pulmonary artery was slightly dilated (Fig. I). The electrocardiogram showed left atrial, left ventricular, and septal hypertrophy. At cardiac catheterization, the mean pulmonary capillary venous pressure was $13 \mathrm{mmHg}$, with an ' $a$ ' wave of 20 , and the pulmonary arterial pressure was 26/1 I $\mathrm{mmHg}$. There was an ' $a$ ' wave of $23 \mathrm{mmHg}$ on the left ventricular pressure trace; the systolic level was 80. There was no systolic gradient between the left ventricle and the aorta in the control state, but after isoprenaline a $30 \mathrm{mmHg}$ difference appeared. Left ventricular cineangiography showed a grossly thickened left ventricle, particularly in the septal region, and the left ventricular cavity was almost obliterated in systole (Fig. 2). The coronary arteries and aorta were normal.

After increasing exercise up to a work load of $500 \mathrm{kpm} /$ minute for 5 minutes on a bicycle ergometer, the pulse rate increased from 80 to 180 a minute. A second exercise test was later carried out; no symptoms occurred at first, but after one to two minutes of rest, the pulse rate slowed and he then developed asystole. Sinus rhythm returned after 30 seconds external cardiac massage and the injection of $0.6 \mathrm{mg}$ atropine sulphate, intravenously. The electrocardiogram was monitored throughout this episode.

In view of the history of recurrent syncope and the documented asystole, it was decided to implant a noncompetitive pacemaker. It was considered that a left ventricular myotomy should be 


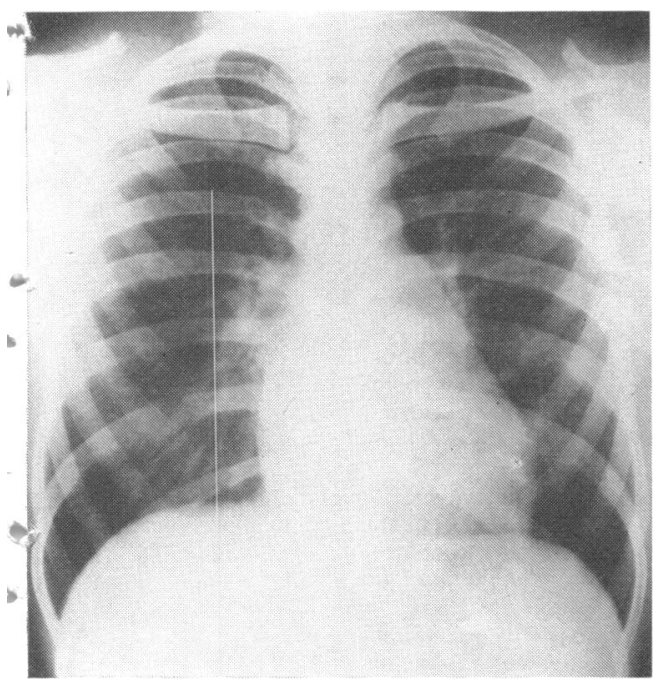

FIG. I Chest x-ray (see text for description).

\section{.}

performed at the same time. At operation, which - was performed by Mr. Donald Ross, pacemaker electrodes were first sutured to the epicardial surface of the heart, and then cardiopulmonary bypass started. On inspection the aortic valve was normal, and below it there were a number of vertical columns of hypertrophied muscle in association with the ventricular septum. Two of these columns were divided and removed. A vertical myotomy was performed on the remaining hypertrophied septum, and a wedge resection on both sides of the myotomy. The non-coronary cusp of the aortic valve was damaged by retraction, and it was necessary to perform a pericardial placement of the cusp. When bypass was hdrawn the aortic valve was competent, but

right atrium remained distended and non$\hat{\imath}$ atractile in spite of stimulation. Satisfactory cardiac action could not be restored despite all attempts at resuscitation.

\section{Discussion}

The cause of syncope and sudden death in Jypertrophic obstructive cardiomyopathy has not been well documented. Goodwin (1964) - considered that ventricular fibrillation was the usual mode of death, and Braunwald et al. (1964), while agreeing that dysrhythmias were the most common cause, emphasized that sudden increase in the obstructive element might occur. Ventricular tachycardia and hibrillation have been recorded in two patients -(Maurice et al., 1966). Atrial tachycardia (Braunwald et al., 1964) and atrial fibrillation are also known to occur (Westlake, Cohen, and Willis, 1962; Shabetai and McGuire, 1963), and atrial fibrillation may cause syncope (Glancy et al., 1970). In obstructive, as opposed to other forms of cardiomyopathy, Hollister and Goodwin (1963) found a low incidence of dysrhythmias, including heart block, throughout long periods of observation, though they had no recordings at the time of syncope or death. Similarly, other workers, who have noted the low incidence of dysrhythmias, appear to have no electrocardiographic recordings at the time of syncope or sudden death (Braunwald et al., 1964; Marriott, 1964; Penther et al., 1966; Meerschwam, 1969).

Johnson (I97I) suggested that, in aortic stenosis, baroceptors in the left ventricular wall may respond to a severe rise in ventricular pressure by initiating a depressor reflex, with bradycardia, peripheral systemic vasodilatation and dilatation of the splanchnic bed. Thus severe hypotension and syncope may be induced. Our patient with hypertrophic obstructive cardiomyopathy developed, possibly due to a similar mechanism, bradycardia and asystole at the onset of syncope. Syncope after exercise is common in these patients, at a time when obstruction to left ventricular outflow is greatest (Whalen et al., 1963; Braunwald et al., 1964; Harrison et al., 1964), and the abolition of syncope after surgical relief of the obstruction supports the thesis that mechanical obstruction may in itself be responsible for the symptom (Ross et al., 1966). Alternatively, ventricular dysrhythmias, including asystole, may cause syncope or death, either with or without an increase in

FIG. 2 Separate frames from the left ventricular cineangiogram in (left) systole, and (right) diastole (see text for explanation).

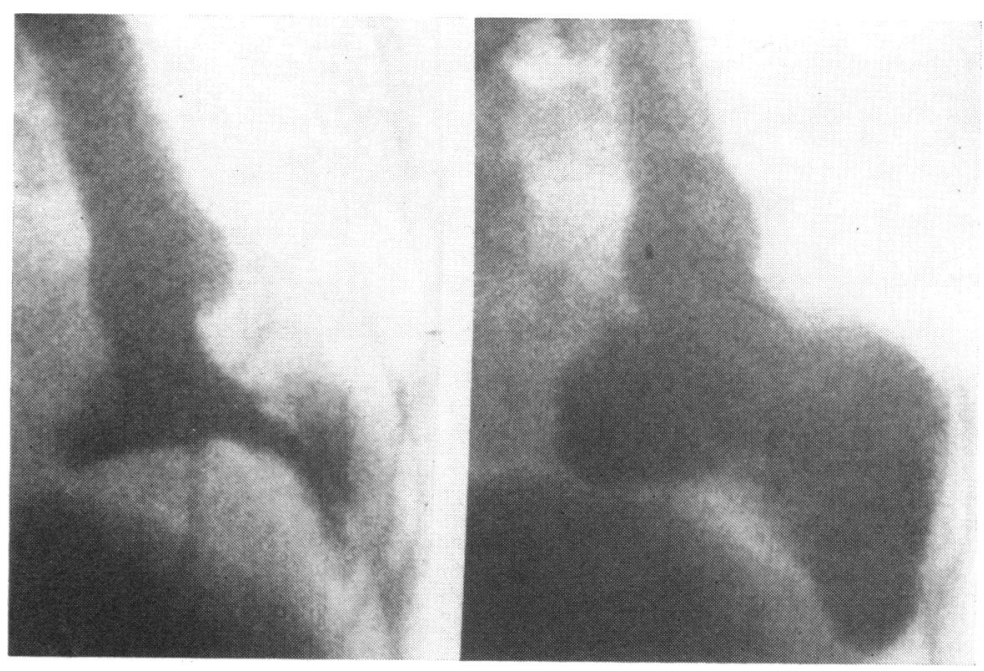


obstruction to left ventricular outflow. Therefore, their demonstration becomes of extreme importance in any patient, since sudden death may be avoided by the prophylactic use of a pacemaker.

\section{References}

Braunwald, E., Lambrew, C. T., Rockoff, S. D., Ross, J., and Morrow, A. G. (I964). Idiopathic hypertrophic subaortic stenosis. A description of the disease based upon an analysis of 64 patients. Circulation, 30, Suppl. 4, 3.

Brent, L. B., Aburano, A., Fisher, D. L., Moran, T. J., Myers, J. D., and Taylor, W. J. (1960). Familial muscular subaortic stenosis. Circulation, 21, 167.

Glancy, D. L., O'Brien, K. P., Gold, H. K., and Epstein, S. E. (1970). Atrial fibrillation in patients with idiopathic hypertrophic subaortic stenosis. British Heart Fournal, 32, 652.

Goodwin, J. F. (1964). Cardiac function in primary myocardial disorders. British Medical fournal, r, 1527.

Goodwin, J. F., Hollman, A., Cleland, W. P., and Teare, D. (1960). Obstructive cardiomyopathy simulating aortic stenosis. British Medical fournal, 22, 403.

Harrison, D. C., Braunwald, E., Glick, G., Mason, D. T., Chidsey, C. A., and Ross, J. (1964). Effects of beta adrenergic blockade on the circulation, with particular reference to observations in patients with hypertrophic subaortic stenosis. Circulation, 29, 84 .

Hollister, R. M., and Goodwin, J. F. (1963). The electrocardiogram in cardiomyopathy. British Heart fournal, 25, 357.

Hollman, A., Goodwin, J. F., Teare, D., and Renwick, J. W. (I960). A family with obstructive cardiomyopathy. British Heart fournal, 22, 449.

Johnson, A. M. (1971). Aortic stenosis, sudden death and the left ventricular baroceptors. British Heart fournal, 33, I.
Marriott, H. J. L. (1964). Electrocardiographic abnormalities, conduction disorders and arrhythmias in primary myocardial disease. Progress in Cardiovascular Diseases, 7, 99.

Maurice, P., Ben-Ismail, M., Penther, Ph., Ferrane, J., and Lenegre, J. (1966). Les myocardopathies obstructives. I. Etude clinique et radiologique. Archives des Maladies du Coeur et des Vaisseaux, 59, 375.

Meerschwam, I. S. (1969). Hypertrophic Obstructive Cardiomyopathy. Excerpta Medica Foundation, Amsterdam.

Penther, Ph., Maurice, P., Ben-Ismail, M., Bourdarias, J.-P., and Lenegre, J. (I966). Les myocardiopathies obstructives. 2. Etude electrocardiographiqie. Archives des Maladies du Coeur et des Vaisseaux, 59, 712.

Ross, J., Braunwald, E., Gault, J. H., Mason, D. T., and Morrow, A. G. (1966). The mechanism of the intraventricular pressure gradient in idiopathic hypertrophic subaortic stenosis. Circulation, 34, 558.

Shabetai, R., and McGuire, J. (1963). Idiopathic cardiac hypertrophy simulating valvular disease. American Heart fournal, 65, 124.

Teare, R. D. (1958). Asymetrical hypertrophy of the heart in young adults. British Heart fournal, 20, $\mathrm{I}$.

Westlake, R. E., Cohen, W., and Willis, W. H. (1962). Wolff-Parkinson-White syndrome and familial cardiomegaly. American Heart Fournal, 64, 314 .

Whalen, R. E., Cohen, A. I., Sumner, R. G., and McIntosh, H. D. (1963). Demonstration of the dynamic nature of idiopathic hypertrophic subaortic stenosis. American fournal of Cardiology, II, 8.

Wigle, E. D., Heimbecker, R. O., and Gunton, R. W. (I962). Idiopathic ventricular septal hypertrophy causing muscular subaortic stenosis. Circulation, 26, 325 .

Requests for reprints to Dr. S. Joseph, National Heart Hospital, Westmorland Street, London WIM 8BA. 